\title{
Comparing Effectiveness Between a Mobile App Program and Traditional Cognitive Behavior Therapy in Obsessive-Compulsive Disorder: Evaluation Study
}

Hyunchan Hwang ${ }^{1}$, MD; Sujin Bae ${ }^{2}, \mathrm{PhD}$; Ji Sun Hong ${ }^{1}, \mathrm{MD}, \mathrm{PhD}$; Doug Hyun Han ${ }^{1}, \mathrm{MD}, \mathrm{PhD}$

${ }^{1}$ Department of Psychiatry, Chung-Ang University Hospital, Seoul, Republic of Korea

${ }^{2}$ Office of Research, Chung-Ang University, Seoul, Republic of Korea

Corresponding Author:

Doug Hyun Han, MD, PhD

Department of Psychiatry

Chung-Ang University Hospital

102, Heukseok-ro, Dongjak-gu

Seoul, 06973

Republic of Korea

Phone: 82262993132

Email: hduk70@gmail.com

\section{Abstract}

Background: This study proposes a digital program for the treatment of mental illness that could increase motivation and improve learning outcomes for patients. Several studies have already applied this method by using an exposure and response prevention-inspired serious game to treat patients with obsessive-compulsive disorder (OCD).

Objective: We hypothesized that a mobile cognitive behavior therapy (CBT) program would be as effective in treating OCD as traditional offline CBT. In addition, the treatment efficacy in response to mobile CBT for OCD might be associated with increased brain activity within the cortico-striato-thalamo-cortical (CSTC) tract.

Methods: The digital CBT treatment program for OCD, OCfree, consists of 6 education sessions, 10 quests, and 7 casual games. Information was gathered from 27 patients with OCD (15 offline CBT and 12 OCfree CBT). During the 6-week intervention period, changes in clinical symptoms and brain function activity were analyzed.

Results: There was no significant difference in the change in OCD symptoms and depressive symptoms between the two groups. However, the OCfree group showed greater improvement in anxiety symptoms compared to the offline CBT group. Both offline CBT and OCfree CBT increased the functional connectivity within the CSTC tract in all patients with OCD. However, CBT using OCfree showed greater changes in brain connectivity within the thalamus and insula, compared to offline CBT.

Conclusions: OCfree, an OCD treatment app program, was effective in the treatment of drug-naïve patients with OCD. The treatment effects of OCfree are associated with increased brain connectivity within the CSTC tract. Multisensory stimulation by education, quests, and games in OCfree increases the activity within the thalamus and insula in patients with OCD.

(JMIR Ment Health 2021;8(1):e23778) doi: 10.2196/23778

\section{KEYWORDS}

obsessive-compulsive disorder; exposure and response prevention; cognitive behavior therapy; cortico-striato-thalamo-cortical tract; functional connectivity; prevention; cognitive; mental illness; behavior therapy

\section{Introduction}

\section{Overview}

Obsessive-compulsive disorder (OCD) is a debilitating mental disorder associated with significant social and occupational impairments [1], affecting 2\%-3\% of the population worldwide [2]. It is diagnosed by the presence of obsessions, compulsions, or both [2]. Obsessions are characterized as intrusive thoughts or images that are often unwanted and repeat constantly. Compulsions, on the other hand, are defined as repetitive behaviors or mental thinking that people feel they need to do, often to counter the obsessions.

Along with obsession and compulsion, functional brain changes in patients with OCD have also been noted. Many studies have 
found the cortico-striato-thalamo-cortical (CSTC) tract to be one of the crucial brain circuits involved in OCD [3,4]. Within the CSTC tract, patients with OCD showed different brain activity in response to various stimuli $[5,6]$. In response to emotion-related tasks, patients with OCD showed overactivation within the anterior cingulate cortex, insula, caudate head, and putamen, which are thought to play a part in salience, arousal, and habit responding [5]. In addition, underactivation was shown in the medial prefrontal cortex and posterior caudate, which are associated with cognitive and behavioral control [5]. Regions outside the CSTC tract are also of interest, as Zhang et al showed altered functional connectivity (FC) in resting-state functional magnetic resonance imaging (Rs-fMRI) between the cerebellum and CSTC circuit in OCD patients [6].

Of several treatment options for OCD, cognitive behavior therapy (CBT) with exposure and response prevention (ERP) is regarded as one of the first choices in many clinical guidelines [7,8]. The National Institute for Health and Care Excellence recommends intensive CBT (over 10 therapist hours including ERP) or a selective serotonin reuptake inhibitor (SSRI) as initial treatment [7]. The American Psychiatric Association also recommends CBT with ERP, SSRIs, or both as first-line treatments [8]. Recent reviews on the literature have found that CBT with ERP has larger effect sizes than pharmacotherapy, although interpreting this as CBT with ERP being better than medication must be avoided as there are many factors to consider [9].

However, CBT with ERP is not without its flaws. One of the main disadvantages of CBT is that it is time consuming, and efficacy is tied to the participant's engagement with the therapy [10]. Moreover, Barnes et al found that homework, one of the key elements of CBT, was one of the main reasons for low adherence because it is linked to negative school homework experiences [10].

Many methods have been devised to overcome this disadvantage. The delivery of mental health services through the internet is one method being considered $[11,12]$. This method has the potential to increase patient engagement and availability [11]. In a randomized controlled trial of family-based treatment for OCD, internet delivered cases showed higher response rates than clinic cases, and this difference persisted after treatment, although the difference was not statistically significant [12]. Another method used is serious games. Eichenberg and Schott argued that serious games could increase motivation and improve learning outcomes, thereby supplementing some of the weaknesses of the conventional internet-mediated health program [13].

Serious games are defined as games developed with a purpose other than entertainment [14]. Notable examples of these are games designed to improve aircrew training [15] or education [16]. Serious games are also used in the medical field to help patients. A meta-analysis and systematic review showed that serious games for mental health were effective in reducing symptoms related to depression, autism spectrum disorder, post-traumatic stress disorder, attention-deficit/hyperactivity disorder, and alcohol use disorder [14]. Serious games have also been shown to lower anxiety and related symptoms. Kim et al reported that a serious game helped lower depression and anxiety in breast cancer patients [17]. A pilot study also showed that a serious game helped reduce anxiety and pain in children before day-care surgery [18]. More recently, Hong et al used an ERP-inspired serious game to treat OCD patients; the patients showed improved OCD symptoms, which correlated with increased brain connectivity between the dorsal anterior cingulate cortex and the prefrontal cortex, after 3 weeks of game play [19].

\section{Hypothesis}

To our knowledge, a mobile app using serious games with both ERP and CBT for OCD has not yet been developed. Therefore, we designed a mobile app based on these theories and conducted a randomized controlled trial comparing the developed program directly with traditional CBT with ERP in OCD patients. We hypothesized that the mobile CBT program would be as effective in the treatment of OCD as traditional offline CBT. In addition, the treatment efficacy in response to mobile CBT for OCD might be associated with increased brain activity within the CSTC tract.

\section{Methods}

\section{Participants}

Through advertisements for treatment of OCD, 32 patients with OCD were recruited from the Department of Psychiatry at Chung-Ang University Hospital. All patients with obsession or compulsion symptoms were screened using the structured Clinical Interview for the Diagnostic and Statistical Manual of Mental Disorders, Fifth Edition (DSM-5), and diagnosed by a psychiatrist (DHH). Inclusion criteria were as follows: (1) age> 18 years, (2) diagnosed with OCD based on DSM-5, (3) drug naïve, and (4) right-handedness. Exclusion criteria were as follows: (1) IQ<80; (2) history of medical or other psychiatric disorders; (3) history of substance use disorders; (4) contraindications to MRI scanning, including claustrophobia or metal implant; and (5) current psychotherapy or medication treatment.

Of the 32 patients with OCD, 1 patient was excluded due to psychotic symptoms of hallucinations. The remaining 31 patients were randomly classified into two groups: an offline CBT group $(n=16)$ and a web-based CBT using OCfree group $(n=15)$. One patient in the offline CBT group and 1 patient in the OCfree group were excluded due to taking medication for anxiety reduction, and another patient in the OCfree group was excluded due to a brain infarction finding in the baseline fMRI. In the OCfree group, 1 patient did not complete the study protocol because they did not want to visit the hospital during the COVID-19 pandemic. Finally, the information of 27 patients with OCD (15 offline CBT and 12 OCfree CBT) was analyzed. Participants who entered the trial received a maximum of 100,000 won (around US \$89) during the whole trial to compensate for travel fees. The institutional review board of Chung-Ang University Hospital approved this study, and all participants provided written informed consent. 


\section{Study Design}

A randomized and treatment-as-usual controlled design was applied for this study. Individual in-person CBT was selected as treatment-as-usual with reference to the American Psychiatric Association practice guidelines [20]. The guideline recommends CBT or medication (SSRI) as the first-line treatment for OCD, states that individual and group CBT seem equally effective, and mentions that internet-delivered CBT is promising and deserving of further research [20]. After screening, all patients with OCD were randomly assigned to receive offline CBT once per week or web-based CBT using OCfree daily for 6 weeks, according to the randomization sequence generated using SPSS version 24.0 (IBM Corp, Armonk, NY, USA), with a 1:1 allocation (offline CBT:CBT using OCfree). At baseline and after intervention, all patients with OCD were assessed with the Korean version of the Yale-Brown Obsessive Compulsive Scale (Y-BOCS) for OCD symptoms [21,22], the Korean version of the Beck Depression Inventory-II (BDI) for depressive symptoms [23,24], and the Korean version of the Beck Anxiety Inventory (BAI) for anxiety symptoms $[25,26]$.

After baseline psychological scales and fMRI data were acquired, the offline CBT group had an hour-long individual session per week with a psychiatrist for 6 weeks. The CBT sessions were designed similarly to the traditional 10-session CBTs but shortened to match the online CBT session numbers. Homework was given and checked for each session.

The OCfree CBT group also had an individual psychiatrist assigned to meet the participant each week and oversee the CBT for 6 weeks. The psychiatrist in the OCfree group used the OCfree program to conduct CBT, and each session lasted approximately 40 minutes. The program has a scheduler system that assigns participants different programs within OCfree for their daily use, and the participant can use different parts of the program as many times as they wish. The psychiatrist would check the program each week for compliance.

\section{OCfree Program}

The mobile app (OCfree) for obsessive-compulsive disorder treatment consists of three categories: education, quests, and serious games. The education category consisted of 6 sessions: (1) learning about OCD: learn about symptoms, causes, and treatments; (2) analyzing obsessions: trigger factors for obsession and compulsive behaviors, compulsive infiltration, fearful ending; (3) understanding strategies with OCD; (4) customized treatment plan; (5) factors for change: a firm resolution; and (6) explanation of cognitive therapy. The learning time of each education session was 20-30 minutes. The quest category consists of 10 subcategories. Those are paired with each education session and supplied to patients as homework: (1) assessment of obsession and compulsion using 65 questions for obsession and 65 questions for compulsion, (2) analyzing the symptoms of obsession and compulsion with 8 panels, (3) understanding false beliefs related to obsession, (4) creating a customized treatment plan for you, (5) preparing for change by yourself, (6) working book for cognitive therapy and 4 adjuvant categories, (7) practice postponing anxiety, (8) ERP using imagination via voice recording, (9) identifying emotions, and (10) practicing choosing. The game category consists of 7 casual games: (1) shooting game, (2) break block game, (3) germ-removing game, (4) doubting and checking game, (5) symmetry and ordering game, (6) numbering and counting game, and (7) mental ritual game (Figure 1).

The shooting game is similar to the fixed shooter arcade game, Galaga. By controlling a spaceship, the players can destroy aliens while avoiding enemies' projectiles. The spaceship is displaced with the object that OCD patients dislike (want to avoid) such as a needle, knife, death, germ, or airplane. The break block game is a modified version of the classic Breakout block game. The players use the paddle to bounce the ball and destroy the bricks. Behind the brick, there is a "word" that is associated with the obsession. When the bricks are completely destroyed, the "word" disappears. Before starting the block game, the OCD patients type the "word" that is associated with the obsession. In the germ-removing game, players can remove pictorial germs represented on the palm of a hand until only one germ remains. The OCD patient should wait 5 seconds before removing the last one. The number of germs increases when the stage is cleared. In the doubting and checking game, players can touch a pictorial faucet on a screen until the number " 1 " is represented. Like the germ-removing game, OCD patients should wait 5 seconds before the last touch (Figure 1). The objects of the checking can change in accordance with the patients' obsessions, including a doorknob and gas valve. In the symmetry and ordering game, players can place books on a bookshelf in accordance with size and color. OCD patients should wait 5 seconds before arranging the last one. More books of various sizes and colors are presented after each stage is cleared. In the numbering and counting game, players type a number that they are preoccupied with. This number is the same as the number of eggs on the screen. The players touch the eggs to hatch them until the last egg remains. The OCD patients should wait 5 seconds before touching the last egg to hatch. In the mental ritual game, players type a word that they are preoccupied with. The word then multiplies and spreads on the screen. Of the multiplied words, $10 \%$ are modified in a different or wrong spelling (one or two characteristics are different), compared to the original spelling. OCD patients should only touch words written in the original spelling. 
Figure 1. OCfree program: (1) learning about OCD: learn about symptoms, causes, and treatments, (2) analyzing obsessions: trigger factors for obsession and compulsive behaviors, compulsive infiltration, fearful ending, (3) understanding strategies with OCD, (4) understanding false beliefs related to obsession, (5) analyzing the symptoms of obsessions and compulsions with 8 panels, (6) creating a customized treatment plan for you, (7) shooting game, (8) break block game, (9) germ-removing game.
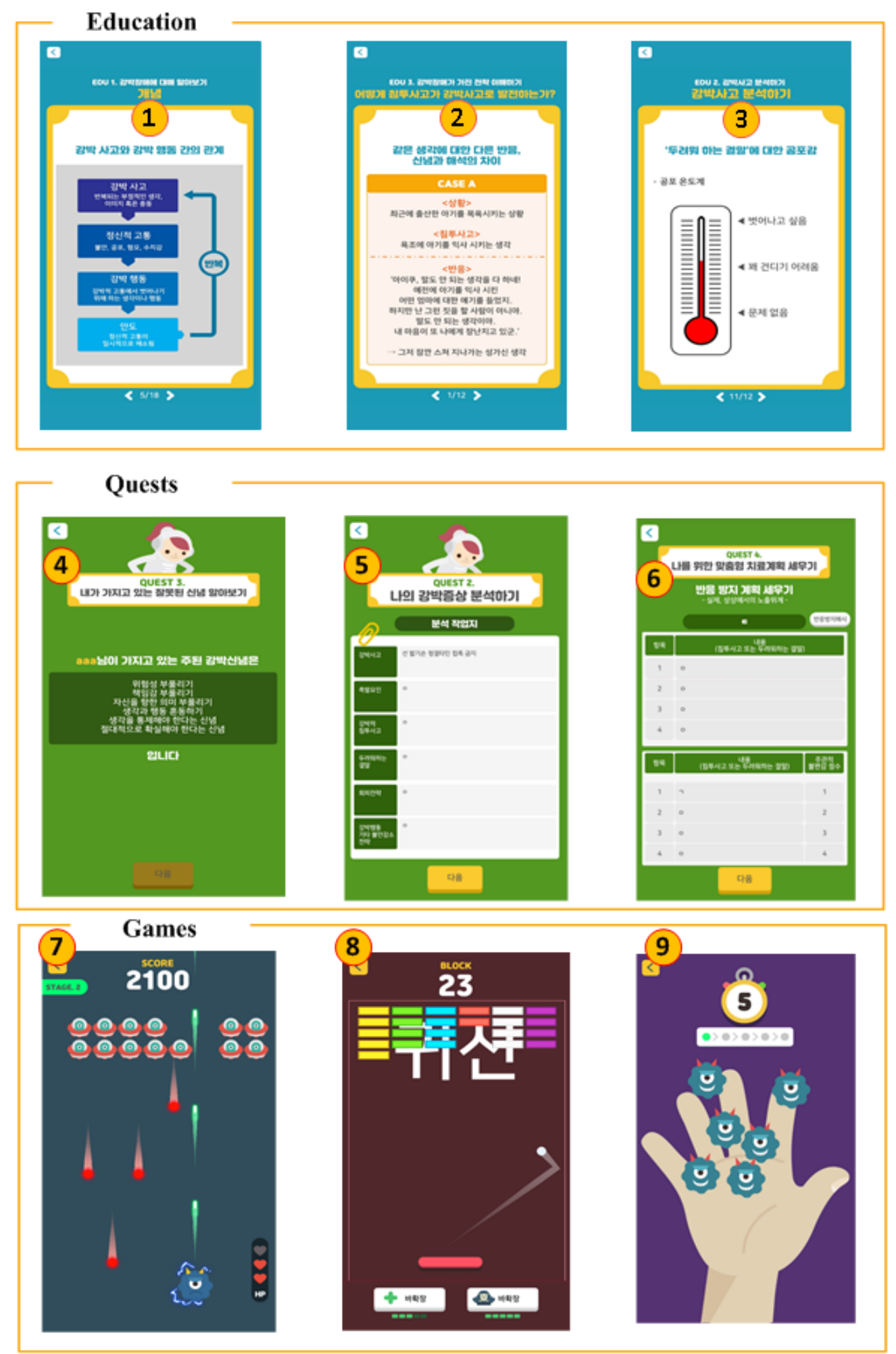

\section{Brain Imaging Data Acquisition and Processing}

A 3.0 Tesla Philips Achieva scanner was used to acquire Rs-MRIs. Only right-handed participants entered the trial due to reports showing functional and anatomical differences in the brain between right- and left-handedness [27]. A total of 230 volumes for 720 seconds were gathered using the following parameters: repetition time/echo time $=3000 / 40$ milliseconds, 40 slices, $64 \times 64$ matrix, $90^{\circ}$ flip angle, 230 -mm field of view, and 3-mm section thickness, without a gap. Using the programs of the Data Processing Assistant for Rs-fMRI [28] and the Rs-fMRI Data Analysis Toolkit (REST) [29], all acquired imaging data were prepared for preprocessing and processing. Brain activity within regions of interest (ROIs) was derived 
from the fractional amplitude of low-frequency fluctuations (fALFF), extracted using REST software. Seed-based FC analysis was performed using the seed ROI extracted from the previous step of correlation comparison between Y-BOCS and fALFF. More details of the fMRI data preprocessing and processing were described in our previous study [30].

\section{Statistical Analysis}

Demographic and clinical characteristics of the offline and OCfree groups were analyzed using the Mann-Whitney U test. The differences in sex ratio and symptom improvement between the two groups were analyzed using a chi-square test. Symptom improvement was defined as a decrease of 2.85 in $25 \%$ of Y-BOCS scores based on a reliable change index of symptoms (standard error of measure $=1.03$, effect size=0.91) [31]. Statistical significance was set at $P<.05$.
The correlation between the fALFF and Y-BOCS scales was calculated using multiple regression analysis in Statistical Parametric Mapping 12 (SPM12; Wellcome Centre for Human Neuroimaging). The changes in fALFF from baseline to 4 weeks in all patients were estimated using a paired $t$ test in SPM12. The differences in the change of fALFF and FC from the thalamus to other brain areas between the offline and OCfree groups were estimated using repeated-measures analysis of variance in SPM12. The ROIs were extracted based on the cluster in the t-map with a defined threshold (uncorrected $P<.001$, voxels $>20$ ).

\section{Results}

\section{Demographic Characteristics and Clinical Scales}

There were no significant differences in age, years of education, Y-BOCS scores, BDI scores, and BAI scores between the offline CBT and OCfree groups at baseline (Table 1).

Table 1. Demographic data and clinical scales.

\begin{tabular}{|c|c|c|}
\hline Characteristic & OCfree group $(n=12)$ & Offline $\mathrm{CBT}^{\mathrm{a}}$ group $(\mathrm{n}=15)$ \\
\hline Age (years), mean (SD) & $25.7(7.7)$ & $24.7(10.7)$ \\
\hline \multicolumn{3}{|l|}{ Sex, $n$} \\
\hline Male & 5 & 6 \\
\hline Female & 7 & 9 \\
\hline Education (years), mean (SD) & $13.3(1.8)$ & $13.8(2.1)$ \\
\hline \multicolumn{3}{|l|}{ Economic status (income) ${ }^{b}, n$} \\
\hline Low & 2 & 3 \\
\hline Middle & 7 & 9 \\
\hline High & 3 & 3 \\
\hline \multicolumn{3}{|l|}{ Y-BOCS ${ }^{\mathbf{c}}$, mean $(\mathrm{SD})$} \\
\hline Pretreatment & $21.9(5.7)$ & $19.5(4.1)$ \\
\hline Posttreatment & $16.7(5.4)$ & $15.9(4.7)$ \\
\hline \multicolumn{3}{|l|}{ BDI $^{\text {d }}$, mean (SD) } \\
\hline Pretreatment & $19.3(4.9)$ & $16.5(11.2)$ \\
\hline Posttreatment & $9.3(5.3)$ & $10.3(9.5)$ \\
\hline \multicolumn{3}{|l|}{$\mathrm{BAI}^{\mathrm{e}}$, mean (SD) } \\
\hline Pretreatment & $19.8(10.7)$ & $16.2(11.7)$ \\
\hline Posttreatment & $9.4(8.6)$ & $11.0(9.4)$ \\
\hline
\end{tabular}

${ }^{\mathrm{a} C B T}$ : cognitive behavior therapy.

${ }^{\mathrm{b}}$ Economic status (income): low, <US \$20,000/year; middle, US \$20,000-40,000/year; high, >US \$40,000/year.

${ }^{\mathrm{c}}$ Y-BOCS: Yale-Brown Obsessive Compulsive Scale.

${ }^{\mathrm{d}}$ BDI: Beck Depression Inventory.

${ }^{\mathrm{e}} \mathrm{BAI}$ : Beck Anxiety Inventory.

The number of improved OCD patients in the OCfree group (improvement vs nonimprovement: $8 / 12,67 \%$ vs $4 / 12,33 \%$ ) was greater than that observed in the offline group $(8 / 15,53 \%$ vs $7 / 15,47 \%$ ), but the difference was not statistically significant $\left(\chi^{2}=0.5 ; P=.69\right)$. There were also no significant differences in the change of Y-BOCS scores $(F=0.50 ; P=.48)$ and BDI scores $(F=2.16 ; P=.16)$ between the two groups. Compared to the offline CBT group, the OCfree group showed greater improvement in BAI scores $(F=5.74 ; P=.02)$ (Figure 2). 
Figure 2. Comparisons of the changes of (A) Y-BOCS, (B) BDI, and (C) BAI scores between the offline CBT group and OCfree group. BAI: Beck Anxiety Inventory. BDI: Beck Depression Inventory. CBT: cognitive behavior therapy. Y-BOCS: Yale-Brown Obsessive Compulsive Scale.
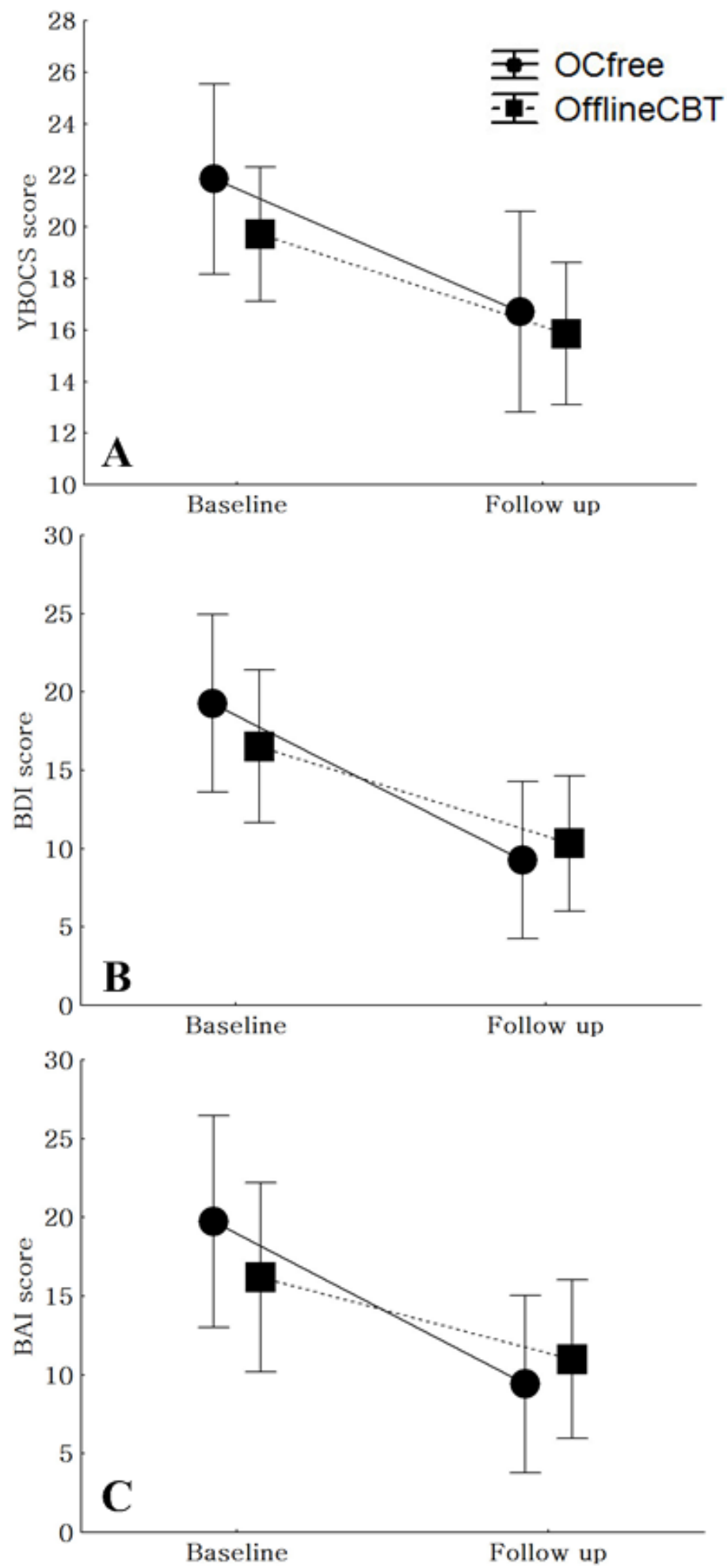

\section{Results of the Program Usage and Satisfaction Survey}

On average, program compliance was $91.4 \%$. The 6 education modules were used 6.0 times each, and the 10 quest modules were used 10.8 times each during the 6 weeks of program usage. The 7 game modules were used, on average, 12.1 times each.

An anonymous survey was taken at the end of the program, and 10 out of 12 participants completed it. The participants were given, among other things, a choice of 1 to 5 stars to measure overall satisfaction, 1 being the lowest and 5 being the highest. The overall satisfaction was 3.4 stars out of 5 . The majority of 2- or 3-star ratings were due to minor errors in the program, giving it a somewhat crude feeling. The 4- and 5-star reviews stated that the program helped them get to know their obsessions and compulsions better. Of the 10 completed surveys, 5 (50\%) said that they would like to continue using the program even 
after the trial, and 7 (70\%) wished to recommend it to other people with similar symptoms. There have been no reports of adverse effects of the program. Adverse effects were checked by the psychiatrist conducting the CBT sessions each week and not asked about in the anonymous survey.

\section{Correlation Between the Y-BOCS Scale and Brain Activity (fALFF)}

In all patients with OCD, Y-BOCS scale scores were negatively correlated with fALFF within the right insular (Talairach code $\mathrm{x}, \mathrm{y}, \mathrm{z}: 48,9,3 ; \mathrm{T}=5.41 ; P_{\text {uncorrected }}<0.001 ; \mathrm{k}_{\mathrm{E}}=20$, Brodmann area [BA] 13), right parietal supramarginal gyrus (x, y, z: 63, -45, 30; T=4.42; $P_{\text {uncorrected }}<0.001 ; \mathrm{k}_{\mathrm{E}}=26$, BA 40), and left thalamus $\left(\mathrm{x}, \mathrm{y}, \mathrm{z}:-9,-21,9 ; \mathrm{T}=4.23 ; P_{\text {uncorrected }}<0.001 ; \mathrm{k}_{\mathrm{E}}=29\right)$ (Figure 3).

Figure 3. Correlation between the Yale-Brown Obsessive Compulsive Scale and brain activity.
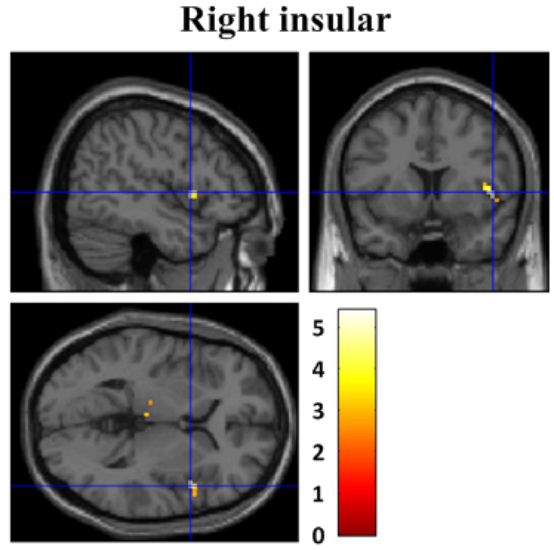

Right supramarginal gyrus
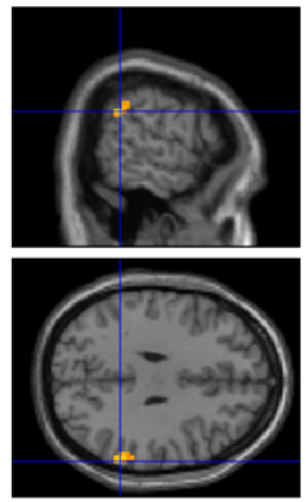
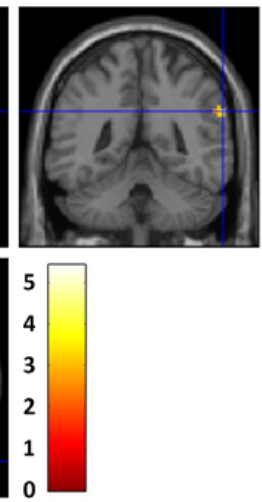

Left thalamus
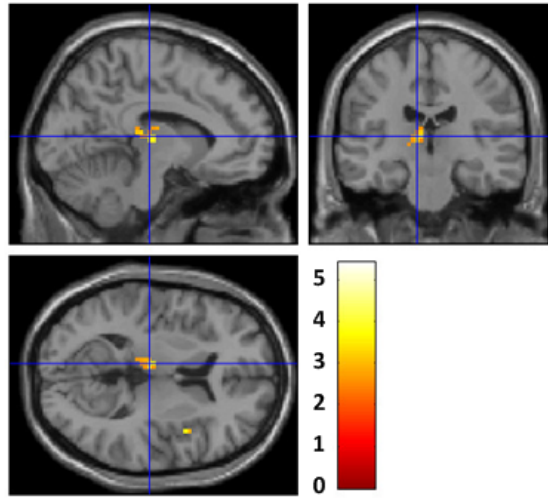

\section{Comparison of the Changes in fALFF Between the OCfree Group and Offline CBT Group}

During the intervention period, the fALFF within the right middle temporal gyrus (x, y, z: 48, -72, 21; $\mathrm{T}=5.50$; $\left.P_{\text {uncorrected }}<0.001 ; \mathrm{k}_{\mathrm{E}}=101, \mathrm{BA} 39\right)$, right middle temporal gyrus (x, y, z: 54, -39, -12; T=4.41; $P_{\text {uncorrected }}<0.001 ; \mathrm{k}_{\mathrm{E}}=73$, BA 20 ), right inferior temporal gyrus (x, y, z: 33, -6, -39; T=4.30; $\left.P_{\text {uncorrected }}<0.001 ; \mathrm{k}_{\mathrm{E}}=216, \mathrm{BA} 20\right)$, right superior frontal gyrus (x, y, z: 15, 54, -9; T=4.24; $P_{\text {uncorrected }}<0.001 ; \mathrm{k}_{\mathrm{E}}=34$, BA 10), left inferior temporal gyrus $(\mathrm{x}, \mathrm{y}, \mathrm{z}:-48,-3,-36$; $\mathrm{T}=4.22$; $P_{\text {uncorrected }}<0.001 ; \mathrm{k}_{\mathrm{E}}=39$, BA 20), and left superior frontal gyrus (x, y, z: $-36,45,33 ; \mathrm{T}=4.02 ; P_{\text {uncorrected }}<0.001 ; \mathrm{k}_{\mathrm{E}}=31$, BA 9) had increased in all patients with OCD (Figure 4).

During the intervention period, the OCfree group showed increased fALFF within the right parahippocampal gyrus (x, y, z: $39,-42,-6 ; \mathrm{T}=4.60 ; P_{\text {uncorrected }}<0.001 ; \mathrm{k}_{\mathrm{E}}=35$, BA 19), compared to the offline CBT group. 
Figure 4. Comparison of the changes in fractional amplitude of low-frequency fluctuations between the OCfree and offline cognitive behavior therapy groups.

Right middle temporal gyrus
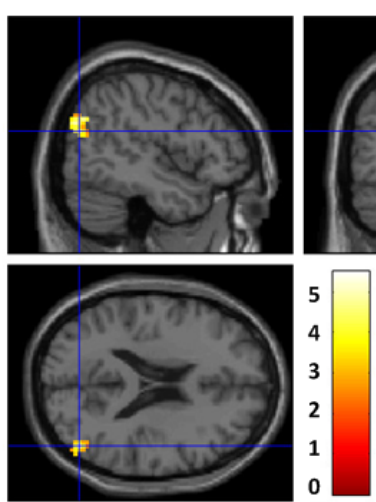

Right superior frontal gyrus
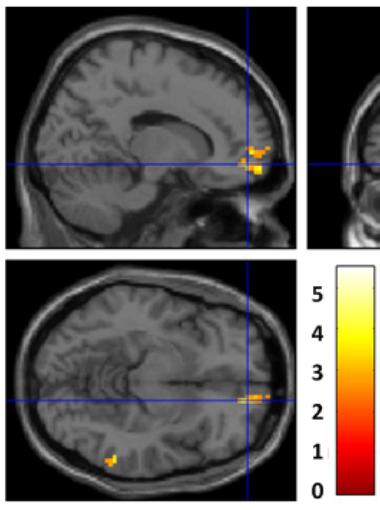

Right middle temporal gyrus
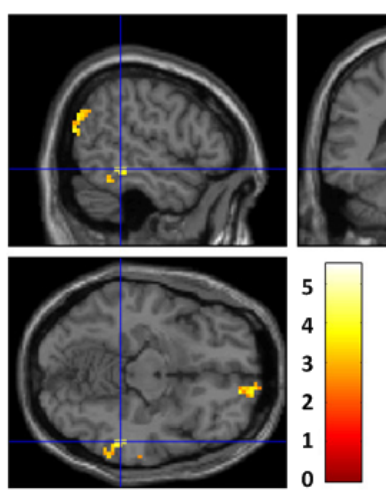

Left inferior temporal gyrus
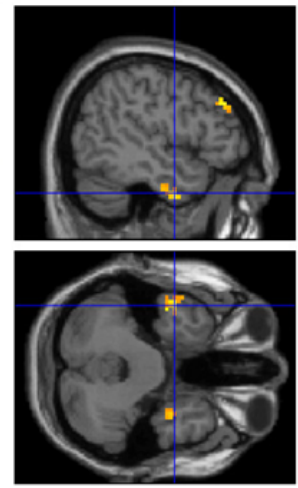
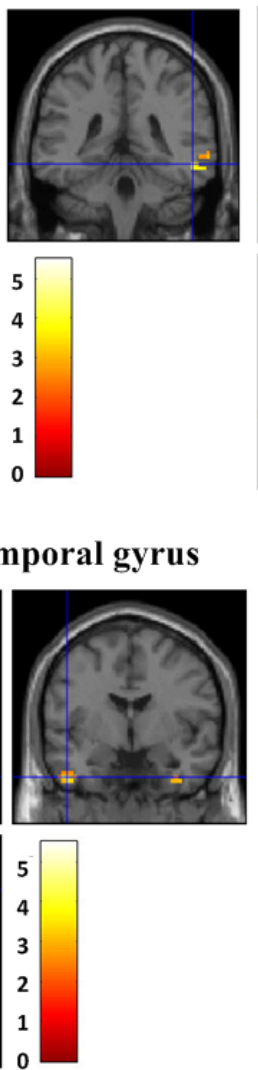

Right inferior temporal gyrus
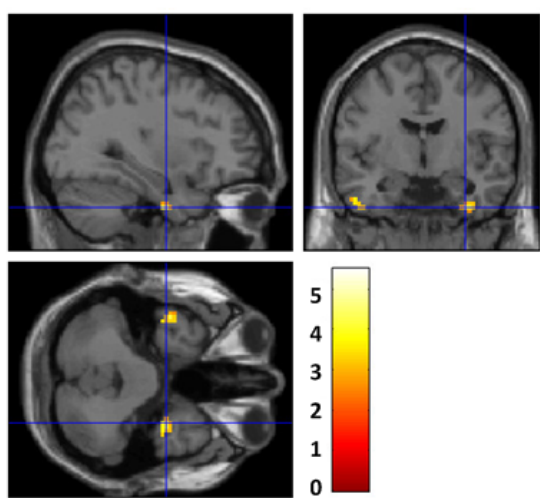

Left superior frontal gyrus
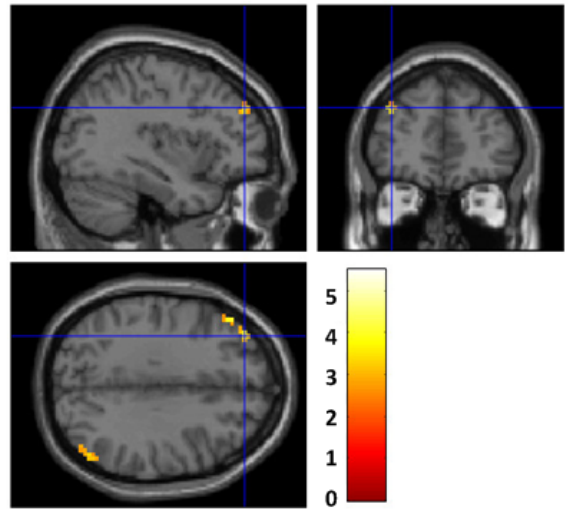

Comparison of the Changes in FC Between the OCfree Group and Offline CBT Group

During the intervention period, the FC from the left thalamus to the right cerebellar tonsil $(\mathrm{x}, \mathrm{y}, \mathrm{z}: 12,-51,-45 ; \mathrm{T}=3.18$;
$\left.P_{\text {uncorrected }}<0.001 ; \mathrm{k}_{\mathrm{E}}=24\right)$, right cerebellar inferior semilunar lobule (x, y, z: 30, -75, -39; T=3.08; $P_{\text {uncorrected }}<0.001 ; \mathrm{k}_{\mathrm{E}}=26$ ), and right insular (x, y, z: 36, 18, 3; T=3.01; $P_{\text {uncorrected }}<0.001$; $\mathrm{k}_{\mathrm{E}}=21$ ) had increased in all patients with OCD (Figure 5).

Figure 5. The changes in functional connectivity in all the patient groups (OCfree and offline cognitive behavior therapy group).
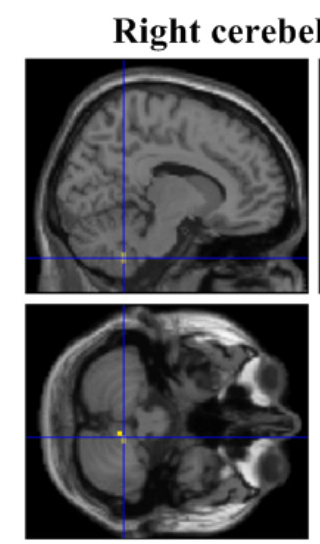

Right inferior semi-lunar lobule
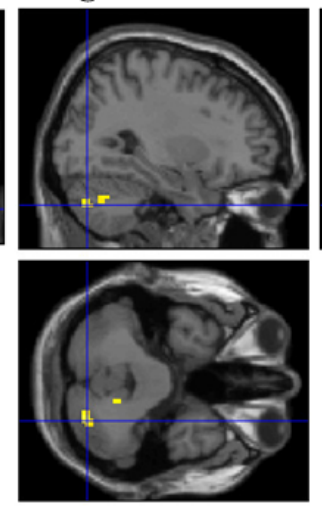
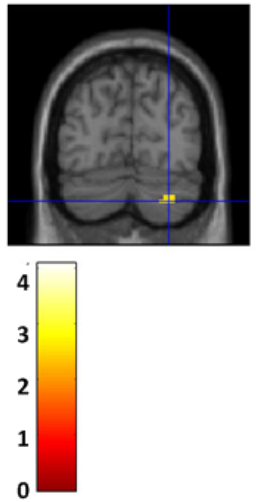

Right insular
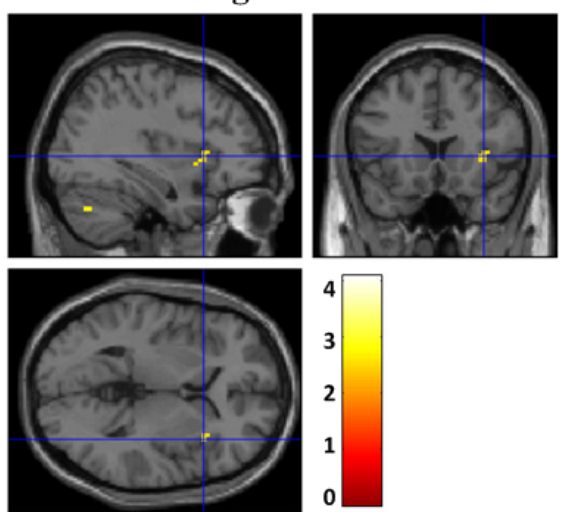

During the intervention period, the FC from the left thalamus to the left frontal rectal gyrus (x, y, z: $-3,24,-33 ; \mathrm{T}=3.51$; $\left.P_{\text {uncorrected }}<0.001 ; \mathrm{k}_{\mathrm{E}}=30\right)$, left inferior frontal gyrus $(\mathrm{x}, \mathrm{y}, \mathrm{z}$ : $-48,39,-12 ; \mathrm{T}=3.39 ; P_{\text {uncorrected }}<0.001 ; \mathrm{k}_{\mathrm{E}}=53$, BA 47), and left occipital lobe (x, y, z: 0, -69, 33; T=3.25; $P_{\text {uncorrected }}<0.001$; $\mathrm{k}_{\mathrm{E}}=39$, BA 7) was increased in the offline CBT group (Figure $6)$. 
Figure 6. Changes in functional connectivity in the offline cognitive behavior therapy group.
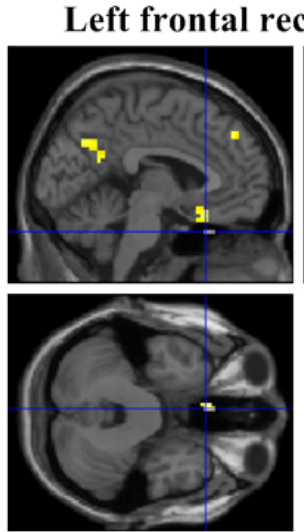

Left inferior frontal gyrus
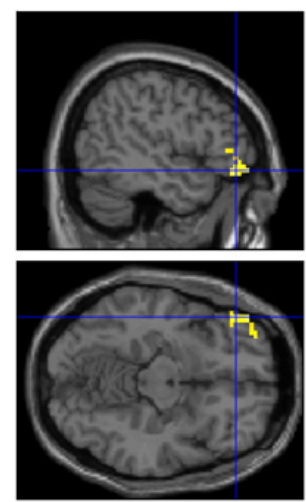
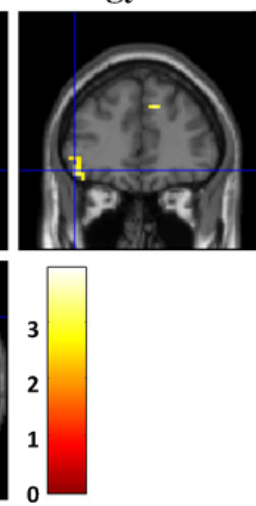

Left occipital lobe
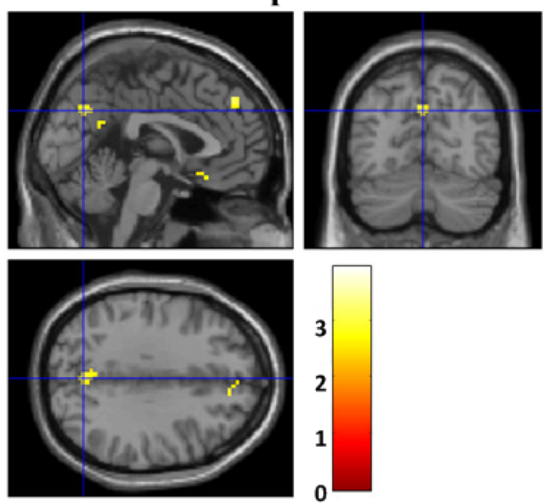

During the intervention period, the FC from the left thalamus to the left occipital lobe $(\mathrm{x}, \mathrm{y}, \mathrm{z}: 0,-63,-51 ; \mathrm{T}=4.18$; $\left.P_{\text {uncorrected }}<0.001 ; \mathrm{k}_{\mathrm{E}}=47, \mathrm{BA} 7\right)$, left frontal rectal gyrus $(\mathrm{x}, \mathrm{y}$, $\mathrm{z}:-6,21,-30 ; \mathrm{T}=3.95 ; P_{\text {uncorrected }}<0.001 ; \mathrm{k}_{\mathrm{E}}=30$, BA 11), right cerebellar posterior lobe $(\mathrm{x}, \mathrm{y}, \mathrm{z}: 36,-81,-45 ; \mathrm{T}=3.71$; $P_{\text {uncorrected }}<0.001 ; \mathrm{k}_{\mathrm{E}}=172$, BA 47), right middle temporal gyrus (x, y, z: 51, -69, 27; T=3.05; $P_{\text {uncorrected }}<0.001 ; \mathrm{k}_{\mathrm{E}}=35$, BA 39), right insular $\left(\mathrm{x}, \mathrm{y}, \mathrm{z}: 36,15,0 ; \mathrm{T}=3.02 ; P_{\text {uncorrected }}<0.001\right.$;
$\mathrm{k}_{\mathrm{E}}=31$ ), and left middle temporal gyrus (x, y, z: $-45,-60,24$; $\mathrm{T}=3.01 ; P_{\text {uncorrected }}<0.001 ; \mathrm{k}_{\mathrm{E}}=39$, BA 39) had increased in the OCfree group (Figure 7).

During the intervention period, the OCfree group showed an increase in FC from the left thalamus to the left insular (x, y, z: $\left.-30,-39,15 ; \mathrm{T}=3.51 ; P_{\text {uncorrected }}<0.001 ; \mathrm{k}_{\mathrm{E}}=34, \mathrm{BA} 13\right)$, compared to the offline CBT group.

Figure 7. Changes in functional connectivity in the OCfree group.

Left occipital lobe
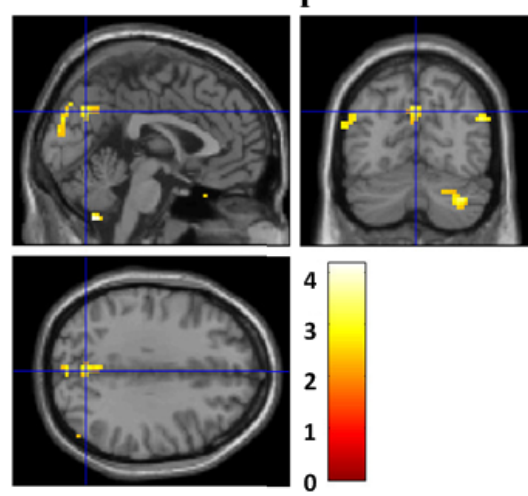

Right middle temporal gyrus
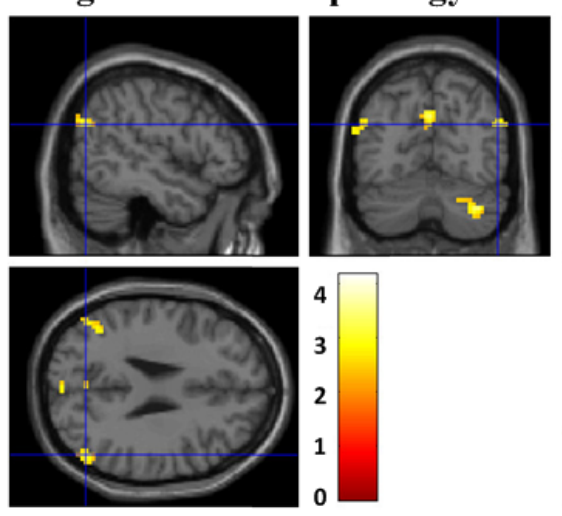

\section{Discussion}

\section{Principal Findings}

OCfree, an OCD treatment app program, was as effective at improving OCD symptoms as offline CBT for OCD. The
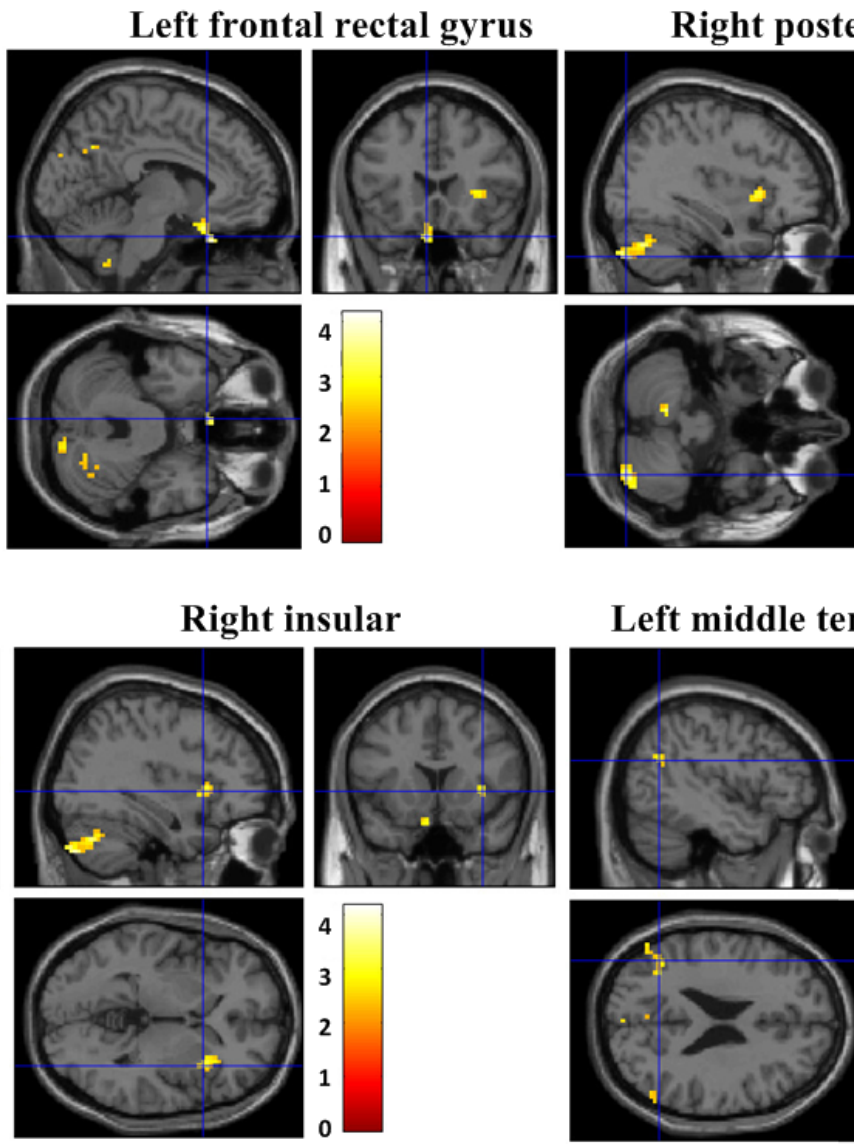
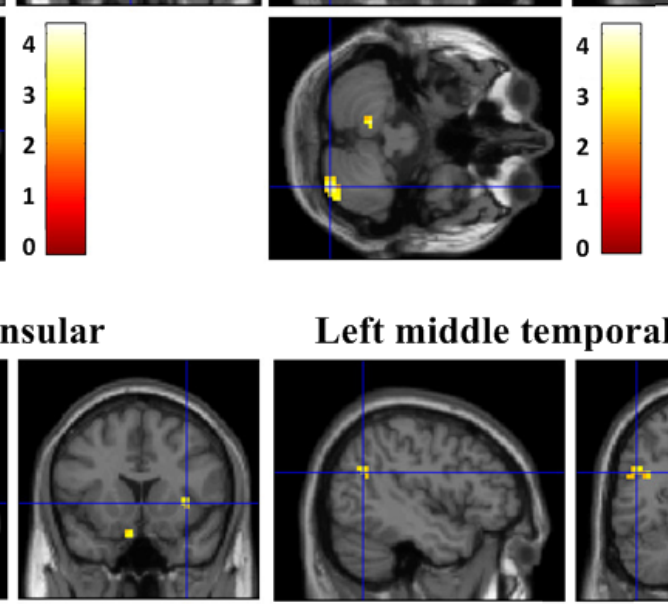

\section{Left middle temporal gyrus}
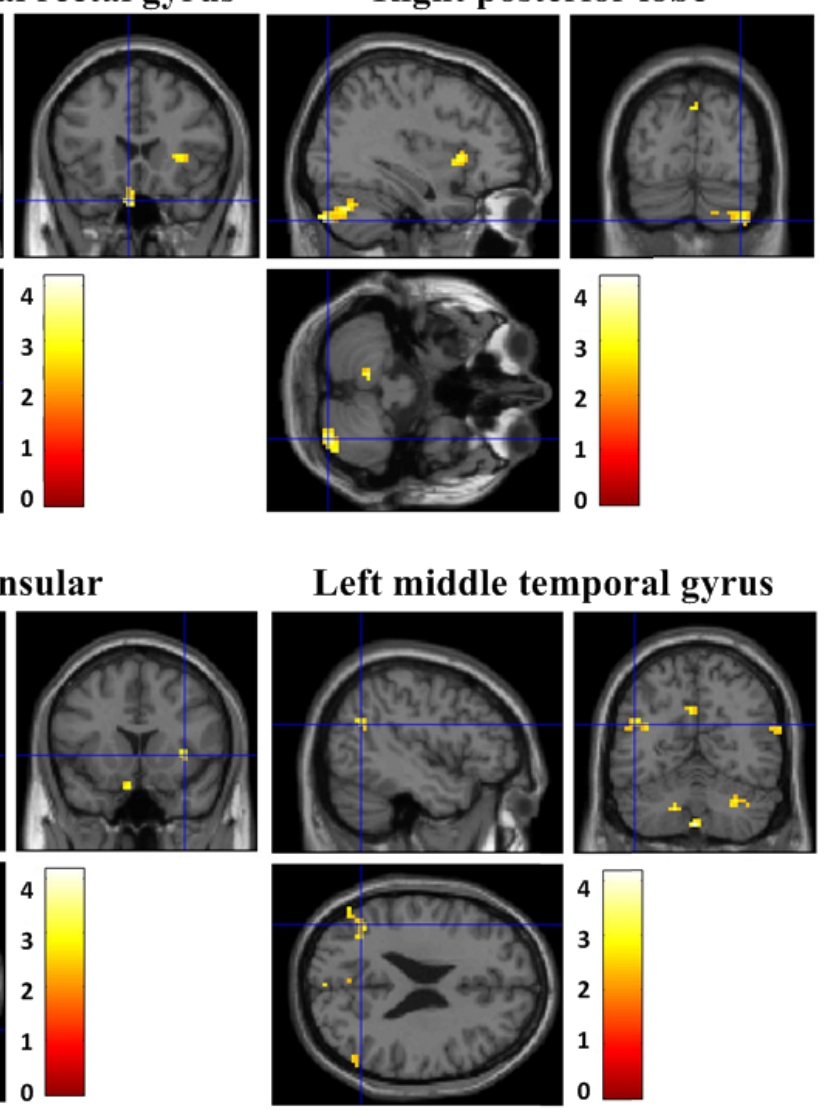

severity of OCD assessed with the Y-BOCS scale in all patients was negatively associated with brain activity within the emotion perception network, including the thalamus and insular. Both offline CBT and OCfree CBT improved OCD symptoms and increased FC within the CSTC tract in all patients with OCD. 
However, CBT using OCfree showed greater changes in fALFF within the thalamus and insular, compared to offline CBT.

\section{The Effectiveness of OCfree, an OCD Treatment Program, on the Improvement of OCD Symptoms}

The OCfree program was as effective as offline CBT for the improvement of OCD symptoms in OCD patients. Overall compliance with OCfree was $91.4 \%$ and overall satisfaction was rated 3.4 out of 5 stars. The internet delivery CBT system for OCD has already been reported to be as effective as offline CBT [12]. In our previous study, an ERP-inspired serious game for OCD improved symptoms in OCD patients [19]. Moreover, OCfree greatly improved anxiety compared to offline CBT. We believe that the OCfree web-based delivery system, including education and quests, may enable easy patient access to the treatment system, and serious games in OCfree may increase interest in treatment, as immersion is thought to be one of the merits of serious games. Easy access and frequent contact with patients in OCD management decrease patient anxiety [32-34]. In mood disorders, internet-assisted cognitive behavioral therapy is becoming an evidence-based cognitive treatment [35]. Serious game-assisted clinical treatments already suggest that serious games can increase affinity and treatment compliance in many areas, including cancer [36], obesity [37], and autism spectrum disorders [38].

\section{Comparison of the Changes in fALFF Between the OCfree and Offline CBT Group}

Comparisons before and after the treatment period in this study showed increased brain activity within the frontal and temporal lobes in all OCD patient groups. Compared to the offline CBT group, the OCfree group showed increased brain activity within the right parahippocampal gyrus. A deficit in emotional perception was reported in patients with OCD [39]. Due to this deficit, repetitive meaningless thoughts occurred in patients with OCD [39]. In several fMRI studies of OCD patients, decreased brain activity within the frontal and temporal lobes has been reported [40,41]. Chen et al reported that patients with OCD showed decreased brain activity within the left medial prefrontal cortex, compared to healthy subjects [42]. In patients with obsessive and compulsive symptoms due to temporal lobe infarction, SSRI treatment would improve the obsessive and compulsive symptoms [43]. The parahippocampal gyrus is known to play a crucial role in the perception of emotion [44]. Within the retrosplenial and posterior cingulate gyri, the parahippocampal gyrus is thought to play a crucial role in facial expression recognition [44]. Taken together, we believe that the OCfree program would improve OCD symptoms in patients with OCD. Moreover, the improvement may be due to the increased brain activity within the brain regions associated with emotional perception.

\section{Comparison of the Changes in FC Between the OCfree and Offline CBT Group}

The brain's FC within the CSTC tract was increased in all patient groups. In several studies, altered (disconnected) brain
FC within the CSTC tract in OCD patients has already been reported $[6,45]$. Based on these results, we suggest that both OCfree and offline CBT may present similar treatment mechanisms of increased FC within the CSTC tract.

Interestingly, compared to the offline CBT group, the OCfree group showed increased brain FC from the thalamus and insular. This result may be associated with various and multiple sources of sensory stimulation via education, quests, and games during play. The thalamus is thought to act as a hub that receives sensory signals from every sensory system and sends them to the associated cortex [46]. The insular functions are associated with sensorimotor processing, socioemotional processing, and cognitive functions [47]. Decreased brain activity within the thalamus [48] and insular [49] have been reported in patients with OCD. Considered together, OCfree with various stimulation systems may increase the thalamus and insular activity, compared to offline CBT. Although there was no difference in the efficacy of treatment between OCfree and offline CBT, future studies with a larger number of subjects may show greater efficacy in symptom improvement with OCfree, compared to offline CBT.

\section{Limitations}

There were several limitations to this study. First, the small sample size and short-term intervention period were not sufficient for generalizing the results. Second, due to the exclusion criteria for medication use, OCD patients with severe anxiety symptoms were excluded from this study. These exceptions can affect the results of the anxiety comparison between the two groups. In addition, although we could not find any individual with co-occurrence of OCD and claustrophobia, lifetime comorbidity between OCD and specific phobias has been reported to be $22 \%$ [50]. Data from a Mexican mental health survey showed that $24.8 \%$ of adolescents with a specific phobia were afraid of closed spaces [51]. For the results of this OCD brain study, OCD patients who experience anxiety in closed spaces were excluded. For this reason, readers should be cautious about generalizing current results. Finally, this study did not recruit a true control group without any formal structured CBT due to ethical limitations. Future studies should recruit a larger number of participants and consider comorbid conditions, including anxiety and mood fluctuations, with a truer control group.

\section{Conclusions}

OCfree, an OCD treatment program, was effective in the treatment of drug-naïve patients with OCD. The treatment effects of OCfree are associated with increased brain connectivity within the CSTC tract. Multisensory stimulation by education, quests, and games in OCfree increased activity within the thalamus and insular regions in patients with OCD. 


\section{Conflicts of Interest}

None declared.

\section{References}

1. Markarian Y, Larson MJ, Aldea MA, Baldwin SA, Good D, Berkeljon A, et al. Multiple pathways to functional impairment in obsessive-compulsive disorder. Clin Psychol Rev 2010 Feb;30(1):78-88. [doi: 10.1016/j.cpr.2009.09.005] [Medline: 19853982]

2. Goodman WK, Grice DE, Lapidus KA, Coffey BJ. Obsessive-compulsive disorder. Psychiatr Clin North Am 2014 Sep;37(3):257-267. [doi: 10.1016/j.psc.2014.06.004] [Medline: 25150561]

3. Li B, Mody M. Cortico-Striato-Thalamo-Cortical Circuitry, Working Memory, and Obsessive-Compulsive Disorder. Front Psychiatry 2016;7:78 [FREE Full text] [doi: 10.3389/fpsyt.2016.00078] [Medline: 27199785]

4. Stein DJ, Costa DLC, Lochner C, Miguel EC, Reddy YCJ, Shavitt RG, et al. Obsessive-compulsive disorder. Nat Rev Dis Primers 2019 Aug 01;5(1):52 [FREE Full text] [doi: 10.1038/s41572-019-0102-3] [Medline: $\underline{31371720}$ ]

5. Rasgon A, Lee W, Leibu E, Laird A, Glahn D, Goodman W, et al. Neural correlates of affective and non-affective cognition in obsessive compulsive disorder: A meta-analysis of functional imaging studies. Eur Psychiatry 2017 Oct;46:25-32. [doi: 10.1016/j.eurpsy.2017.08.001] [Medline: 28992533]

6. Zhang H, Wang B, Li K, Wang X, Li X, Zhu J, et al. Altered Functional Connectivity Between the Cerebellum and the Cortico-Striato-Thalamo-Cortical Circuit in Obsessive-Compulsive Disorder. Front Psychiatry 2019;10:522 [FREE Full text] [doi: 10.3389/fpsyt.2019.00522] [Medline: $\underline{31396115]}$

7. National Institute for Health and Clinical Excellence (NICE). Obsessive-compulsive disorder and body dysmorphic disorder: treatment. Clinical guideline CG31. 2005 Nov 29. URL: https://www.nice.org.uk/guidance/cg31/resources/ obsessivecompulsive-disorder-and-body-dysmorphic-disorder-treatment-pdf-975381519301 [accessed 2020-11-20]

8. Koran L, Hanna G, Hollander E, Nestadt G, Simpson H, American Psychiatric Association. Practice guideline for the treatment of patients with obsessive-compulsive disorder. Am J Psychiatry 2007 Jul;164(7 Suppl):5-53 [FREE Full text] [Medline: $\underline{17849776]}$

9. Hirschtritt ME, Bloch MH, Mathews CA. Obsessive-Compulsive Disorder: Advances in Diagnosis and Treatment. JAMA 2017 Apr 04;317(13):1358-1367. [doi: 10.1001/jama.2017.2200] [Medline: 28384832]

10. Barnes M, Sherlock S, Thomas L, Kessler D, Kuyken W, Owen-Smith A, et al. No pain, no gain: depressed clients' experiences of cognitive behavioural therapy. Br J Clin Psychol 2013 Nov;52(4):347-364. [doi: 10.1111/bjc.12021] [Medline: 24117909]

11. Price M, Yuen EK, Goetter EM, Herbert JD, Forman EM, Acierno R, et al. mHealth: a mechanism to deliver more accessible, more effective mental health care. Clin Psychol Psychother 2014;21(5):427-436 [FREE Full text] [doi: 10.1002/cpp.1855] [Medline: 23918764]

12. Comer JS, Furr JM, Kerns CE, Miguel E, Coxe S, Elkins RM, et al. Internet-delivered, family-based treatment for early-onset OCD: A pilot randomized trial. J Consult Clin Psychol 2017 Feb;85(2):178-186 [FREE Full text] [doi: 10.1037/ccp0000155] [Medline: 27869451]

13. Eichenberg C, Schott M. Serious Games for Psychotherapy: A Systematic Review. Games Health J 2017 Jun;6(3):127-135. [doi: 10.1089/g4h.2016.0068] [Medline: 28628385]

14. Lau HM, Smit JH, Fleming TM, Riper H. Serious Games for Mental Health: Are They Accessible, Feasible, and Effective? A Systematic Review and Meta-analysis. Front Psychiatry 2016;7:209 [FREE Full text] [doi: 10.3389/fpsyt.2016.00209] [Medline: 28149281]

15. Mautone T, Spiker V, Karp D. Using serious game technology to improve aircrew training. 2008 Dec Presented at: Interservice/Industry Training, Simulation \& Education Conference; 2008; Orlando, Florida, US p. 1-11 URL: https:/ /mfonakpan.com/wp-content/uploads/2019/08/Using-Serious-Game-Technology-to-Improve-Aircrew-Training-1.pdf

16. Schäfer A, Holz J, Leonhardt T, Schroeder U, Brauner P, Ziefle M. From boring to scoring - a collaborative serious game for learning and practicing mathematical logic for computer science education. Computer Science Education 2013 Jun;23(2):87-111. [doi: 10.1080/08993408.2013.778040]

17. Kim SM, Kim H, Hwang HC, Hong JS, Bae S, Min KJ, et al. The Effects of a Serious Game on Depressive Symptoms and Anxiety in Breast Cancer Patients with Depression: A Pilot Study Using Functional Magnetic Resonance Imaging. Games Health J 2018 Dec;7(6):409-417. [doi: 10.1089/g4h.2017.0183] [Medline: $\underline{30383458]}$

18. Matthyssens LE, Vanhulle A, Seldenslach L, Vander Stichele G, Coppens M, Van Hoecke E. A pilot study of the effectiveness of a serious game CliniPup® on perioperative anxiety and pain in children. J Pediatr Surg 2020 Feb;55(2):304-311. [doi: 10.1016/j.jpedsurg.2019.10.031] [Medline: 31761458]

19. Hong JS, Kim SM, Aboujaoude E, Han DH. Investigation of a Mobile "Serious Game" in the Treatment of Obsessive-Compulsive Disorder: A Pilot Study. Games Health J 2018 Oct;7(5):317-326. [doi: 10.1089/g4h.2017.0158] [Medline: $\underline{30129775]}$ 
20. Koran L, Simpson H. Guideline watch (March 2013): practice guideline for the treatment of patients with obsessive-compulsive disorder.: American Psychiatric Association; 2013 Mar. URL: https://psychiatryonline.org/pb/assets/ raw/sitewide/practice guidelines/guidelines/ocd-watch.pdf [accessed 2020-11-20]

21. Goodman WK. The Yale-Brown Obsessive Compulsive Scale. Arch Gen Psychiatry 1989 Nov 01;46(11):1006. [doi: 10.1001/archpsyc.1989.01810110048007]

22. Seol S, Kwon JS, Shin M. Korean self-report version of the yale-brown obsessive-compulsive scale: factor structure, reliability, and validity. Psychiatry Investig 2013 Mar;10(1):17-25 [FREE Full text] [doi: 10.4306/pi.2013.10.1.17] [Medline: 23482407]

23. Beck AT, Steer RA, Ball R, Ranieri WF. Comparison of Beck Depression Inventories -IA and -II in psychiatric outpatients. J Pers Assess 1996 Dec;67(3):588-597. [doi: 10.1207/s15327752jpa6703_13] [Medline: 8991972]

24. Lim SY, Lee EJ, Jeong SW, Kim HC, Jeong CH, Jeon TY, et al. The validation study of Beck Depression Scale 2 in Korean version. Anxiety and Mood 2011 Apr 30;7(1):48-53 [FREE Full text]

25. Beck AT, Epstein N, Brown G, Steer RA. An inventory for measuring clinical anxiety: psychometric properties. J Consult Clin Psychol 1988 Dec;56(6):893-897. [doi: 10.1037//0022-006x.56.6.893] [Medline: 3204199]

26. Lee HK, Kim J, Hong S, Lee EH, Hwang ST. Psychometric Properties of the Beck Anxiety Inventory in the Community-dwelling Sample of Korean Adults. Korean Journal of Clinical Psychology 2016 Nov;35(4):822-830. [doi: 10.15842/kjcp.2016.35.4.010]

27. Hatta T. Handedness and the brain: a review of brain-imaging techniques. Magn Reson Med Sci 2007;6(2):99-112 [FREE Full text] [doi: 10.2463/mrms.6.99] [Medline: 17690540]

28. Chao-Gan Y, Yu-Feng Z. DPARSF: A MATLAB Toolbox for "Pipeline" Data Analysis of Resting-State fMRI. Front Syst Neurosci 2010;4:13 [FREE Full text] [doi: 10.3389/fnsys.2010.00013] [Medline: 20577591]

29. Song X, Dong Z, Long X, Li S, Zuo X, Zhu C, et al. REST: a toolkit for resting-state functional magnetic resonance imaging data processing. PLoS One 2011;6(9):e25031 [FREE Full text] [doi: 10.1371/journal.pone.0025031] [Medline: 21949842]

30. Hwang H, Hong J, Kim SM, Han DH. The correlation between family relationships and brain activity within the reward circuit in adolescents with Internet gaming disorder. Sci Rep 2020 Jun 19;10(1):9951 [FREE Full text] [doi: 10.1038/s41598-020-66535-3] [Medline: $\underline{\text { 32561779] }}$

31. Pallanti S, Hollander E, Bienstock C, Koran L, Leckman J, Marazziti D, International Treatment Refractory OCD Consortium. Treatment non-response in OCD: methodological issues and operational definitions. Int J Neuropsychopharmacol 2002 Jun;5(2):181-191 [FREE Full text] [doi: 10.1017/S1461145702002900] [Medline: 12135542]

32. Kyrios M, Ahern C, Fassnacht DB, Nedeljkovic M, Moulding R, Meyer D. Therapist-Assisted Internet-Based Cognitive Behavioral Therapy Versus Progressive Relaxation in Obsessive-Compulsive Disorder: Randomized Controlled Trial. J Med Internet Res 2018 Aug 08;20(8):e242 [FREE Full text] [doi: 10.2196/jmir.9566] [Medline: 30089607]

33. Rück C, Lundström L, Flygare O, Enander J, Bottai M, Mataix-Cols D, et al. Study protocol for a single-blind, randomised controlled, non-inferiority trial of internet-based versus face-to-face cognitive behaviour therapy for obsessive-compulsive disorder. BMJ Open 2018 Sep 05;8(9):e022254 [FREE Full text] [doi: 10.1136/bmjopen-2018-022254] [Medline: 30185575]

34. Olthuis JV, Watt MC, Bailey K, Hayden JA, Stewart SH. Therapist-supported Internet cognitive behavioural therapy for anxiety disorders in adults. Cochrane Database Syst Rev 2016 Mar 12;3:CD011565 [FREE Full text] [doi: 10.1002/14651858.CD011565.pub2] [Medline: 26968204]

35. Andersson G, Carlbring P. Internet-Assisted Cognitive Behavioral Therapy. Psychiatr Clin North Am 2017 Dec;40(4):689-700. [doi: 10.1016/j.psc.2017.08.004] [Medline: 29080594]

36. Loerzel V, Clochesy J, Geddie P. Using a community advisory board to develop a serious game for older adults undergoing treatment for cancer. Appl Nurs Res 2018 Feb;39:207-210 [FREE Full text] [doi: 10.1016/j.apnr.2017.11.030] [Medline: 29422160]

37. Dias JD, Mekaro MS, Cheng Lu JK, Otsuka JL, Fonseca LMM, Zem-Mascarenhas SH. Serious game development as a strategy for health promotion and tackling childhood obesity. Rev Lat Am Enfermagem 2016 Aug 15;24:e2759 [FREE Full text] [doi: 10.1590/1518-8345.1015.2759] [Medline: 27533268]

38. Tang JSY, Falkmer M, Chen NTM, B lte S, Girdler S. Designing a Serious Game for Youth with ASD: Perspectives from End-Users and Professionals. J Autism Dev Disord 2019 Mar;49(3):978-995. [doi: 10.1007/s10803-018-3801-9] [Medline: 30377883]

39. Zetsche U, Rief W, Westermann S, Exner C. Cognitive deficits are a matter of emotional context: inflexible strategy use mediates context-specific learning impairments in OCD. Cogn Emot 2015;29(2):360-371. [doi: 10.1080/02699931.2014.911144] [Medline: 24801151]

40. Hu X, Zhang L, Bu X, Li H, Li B, Tang W, et al. Localized Connectivity in Obsessive-Compulsive Disorder: An Investigation Combining Univariate and Multivariate Pattern Analyses. Front Behav Neurosci 2019;13:122 [FREE Full text] [doi: 10.3389/fnbeh.2019.00122] [Medline: 31249515]

41. Xia J, Fan J, Du H, Liu W, Li S, Zhu J, et al. Abnormal spontaneous neural activity in the medial prefrontal cortex and right superior temporal gyrus correlates with anhedonia severity in obsessive-compulsive disorder. J Affect Disord 2019 Dec 01;259:47-55. [doi: 10.1016/j.jad.2019.08.019] [Medline: $\underline{31437701]}$ 
42. Chen Y, Ou Y, Lv D, Yang R, Li S, Jia C, et al. Altered network homogeneity of the default-mode network in drug-naive obsessive-compulsive disorder. Prog Neuropsychopharmacol Biol Psychiatry 2019 Jul 13;93:77-83. [doi: 10.1016/j.pnpbp.2019.03.008] [Medline: $\underline{30905622]}$

43. Muneoka K, Shirayama Y, Kon K, Kawabe M, Kimura S. Delayed-onset obsessive-compulsive symptoms after brain infarctions treated with paroxetine. Clin Neuropharmacol 2011;34(6):260-261. [doi: 10.1097/WNF.0b013e3182329670] [Medline: 22104637]

44. Bègue I, Vaessen M, Hofmeister J, Pereira M, Schwartz S, Vuilleumier P. Confidence of emotion expression recognition recruits brain regions outside the face perception network. Soc Cogn Affect Neurosci 2019 Jan 04;14(1):81-95 [FREE Full text] [doi: $10.1093 / \mathrm{scan} / \mathrm{nsy} 102]$ [Medline: $\underline{30481350]}$

45. Tian L, Meng C, Jiang Y, Tang Q, Wang S, Xie X, et al. Abnormal functional connectivity of brain network hubs associated with symptom severity in treatment-naive patients with obsessive-compulsive disorder: A resting-state functional MRI study. Prog Neuropsychopharmacol Biol Psychiatry 2016 Apr 03;66:104-111. [doi: 10.1016/j.pnpbp.2015.12.003] [Medline: 26683173]

46. Gazzaniga M, Ivry RB, Mangun GR. Cognitive Neuroscience: The Biology of the Mind. 4th Edition. New York: W. W. Norton \& Company; 2013.

47. Uddin LQ, Nomi JS, Hébert-Seropian B, Ghaziri J, Boucher O. Structure and Function of the Human Insula. J Clin Neurophysiol 2017 Jul;34(4):300-306 [FREE Full text] [doi: 10.1097/WNP.0000000000000377] [Medline: 28644199]

48. Niu Q, Yang L, Song X, Chu C, Liu H, Zhang L, et al. Abnormal resting-state brain activities in patients with first-episode obsessive-compulsive disorder. Neuropsychiatr Dis Treat 2017;13:507-513 [FREE Full text] [doi: 10.2147/NDT.S117510] [Medline: 28243104]

49. Zhu Y, Fan Q, Zhang H, Qiu J, Tan L, Xiao Z, et al. Altered intrinsic insular activity predicts symptom severity in unmedicated obsessive-compulsive disorder patients: a resting state functional magnetic resonance imaging study. BMC Psychiatry 2016 Apr 16;16:104 [FREE Full text] [doi: 10.1186/s12888-016-0806-9] [Medline: 27084762]

50. Pallanti S, Grassi G, Sarrecchia ED, Cantisani A, Pellegrini M. Obsessive-compulsive disorder comorbidity: clinical assessment and therapeutic implications. Front Psychiatry 2011;2:70 [FREE Full text] [doi: 10.3389/fpsyt.2011.00070] [Medline: 22203806]

51. Benjet C, Borges G, Stein DJ, Méndez E, Medina-Mora ME. Epidemiology of fears and specific phobia in adolescence: results from the Mexican Adolescent Mental Health Survey. J Clin Psychiatry 2012 Feb;73(2):152-158. [doi: 10.4088/JCP.11m07442] [Medline: 22401475]

\author{
Abbreviations \\ BA: Brodmann area \\ BAI: Beck Anxiety Inventory \\ BDI: Beck Depression Inventory \\ CBT: cognitive behavior therapy \\ CSTC: cortico-striato-thalamo-cortical \\ DSM-5: Diagnostic and Statistical Manual of Mental Disorders, Fifth Edition \\ ERP: exposure and response prevention \\ fALFF: fractional amplitude of low-frequency fluctuations \\ OCD: obsessive-compulsive disorder \\ REST: Resting-state functional magnetic resonance imaging Data Analysis Toolkit \\ ROI: region of interest \\ Rs-fMRI: resting-state functional magnetic resonance imaging \\ SPM12: Statistical Parametric Mapping 12 \\ SSRI: selective serotonin reuptake inhibitor \\ Y-BOCS: Yale-Brown Obsessive Compulsive Scale
}

Edited by J Torous; submitted 06.09.20; peer-reviewed by M Choy, C Wilks; comments to author 19.10.20; revised version received
19.11.20; accepted 20.11.20; published 19.01.21
Please cite as:
Hwang H, Bae S, Hong JS, Han DH
Comparing Effectiveness Between a Mobile App Program and Traditional Cognitive Behavior Therapy in Obsessive-Compulsive
Disorder: Evaluation Study
JMIR Ment Health $2021 ; 8(1): e 23778$
URL: $\underline{\text { http://mental.jmir.org/2021/1/e23778/ }}$
doi: $\underline{10.2196 / 23778}$
PMID: $\underline{3464208}$


(CHyunchan Hwang, Sujin Bae, Ji Sun Hong, Doug Hyun Han. Originally published in JMIR Mental Health (http://mental.jmir.org), 19.01.2021. This is an open-access article distributed under the terms of the Creative Commons Attribution License (https://creativecommons.org/licenses/by/4.0/), which permits unrestricted use, distribution, and reproduction in any medium, provided the original work, first published in JMIR Mental Health, is properly cited. The complete bibliographic information, a link to the original publication on http://mental.jmir.org/, as well as this copyright and license information must be included. 